\title{
The Upsurge of COVID-19 Cases Amidst the Reopening of Schools in Ghana: The Role of Teachers as Frontline Workers
}

\author{
Eric Twum Ampofo ${ }^{1,}$ *, Robert Ampomah ${ }^{2}$, Papa Kofi Amissah-Reynolds ${ }^{3}$, Samuel Ebo Owusu ${ }^{4}$, \\ Michael Opoku-Manu ${ }^{5}$ \\ ${ }^{1}$ Department of Educational Studies, University of Education, Winneba, Ghana \\ ${ }^{2}$ Department of Interdisciplinary Studies, University of Education, Winneba, Ghana \\ ${ }^{3}$ Department of Science Education, University of Education, Winneba, Ghana \\ ${ }^{4}$ Department of Crop and Soil Sciences Education, University of Education, Winneba, Ghana \\ ${ }^{5}$ Department of Social Science, Catholic University College, Sunyani, Ghana
}

Email address:

twumampofo.eric@yahoo.com (E. T. Ampofo),rampomah5@yahoo.com (R. Ampomah),

kofireynolds@gmail.com (P. K. Amissah-Reynolds), ebow4c@gmail.com (S. E. Owusu), sasfynba@gmail.com (M. Opoku-Manu)

${ }^{*}$ Corresponding author

\section{To cite this article:}

Eric Twum Ampofo, Robert Ampomah, Papa Kofi Amissah-Reynolds, Samuel Ebo Owusu, Michael Opuku-Manu. The Upsurge of COVID19 Cases Amidst the Reopening of Schools in Ghana: The Role of Teachers as Frontline Workers. International Journal of Secondary Education. Vol. 8, No. 3, 2020, pp. 96-102. doi: 10.11648/j.ijsedu.20200803.13

Received: August 3, 2020; Accepted: August 17, 2020; Published: August 25, 2020

\begin{abstract}
The novel coronavirus disease is a global pandemic and gradually teachers are beginning to find themselves on the frontline of educational delivery as lots of countries, including Ghana, ease up restrictions and reopen schools. The main aim of this article was to present evidence to validate teachers' role as frontline workers amid rising cases of COVID-19. Also, we looked at the measures the government put in place prior to the reopening vis-a-vis their adequacy. Again, we examined reasons for the emerging increase in cases of COVID-19 infections among teachers and strategies to overcome this problem. So far, available evidence suggest that about $24 \%$ of teachers are being increasingly infected with the novel disease. Major factors accounting for COVID-19 infections among teachers include inadequate preparation before reopening of schools, a lack of understanding of the epidemiology of the disease, unavailability of PPEs, and psychological stress. We, therefore recommend that protection of students, teachers and non-teaching staff should be of topmost priority of the government through the education and training, provision of appropriate incentives, provision of PPEs and the requisite psychological support.
\end{abstract}

Keywords: COVID-19, Teachers' Role, Teachers' Preparation, Infection Among Teachers, Impact of Education, Students' Indifference

\section{Introduction}

At the start of the year 2020, the World has gone from unearthing the presence of an indigenous virus in Wuhan, the Hubei Province of China to a worldwide pandemic [10]. The World Health Organisation, on March 11 2020, declared the novel COVID-19 a global pandemic after 118,000 infections and 4,291 deaths were recorded in 114 countries which included six African countries [17]. Following the pronouncement that the infection would spread rapidly across countries, resulting in severe morbidity and mortality in a cross-section of the populace terrified the whole world. Therefore various governments had to swiftly devise sound policy guidelines in order to limit the spread of the disease [8]. On March 12 2020, Ghana recorded her first two cases and after three months she had a total of 10,856 confirmed cases with 44 related deaths $[1,19,24]$. Bearing in mind of the date Ghana recorded her first case and the state of current statistics indicates that Ghana has witnessed a speedy and shocking day-to-day upsurge. 
According to the WHO as of 12 June 2020, about 7.6 million people have been confirmed to be infected with the disease worldwide with approximately 430,000 deaths recorded [24]. Undoubtedly, the COVID-19 global contagion has shown to the world that no governments from either developed or developing nations were prepared to prevent and/or manage this novel disease [18]. The viral infection first hit China, followed by Europe and moved to the South and East Mediterranean, Africa and other parts of the world. Researchers believe that COVID-19 is spread through droplets from an infected person. When such droplets fall on surfaces and someone comes in contact with it, mostly with the hand and thereafter touches the nose or the mouth with the hand, such a person would be infected with the virus [10]. As a result physicians hypothesize that physical/social distancing remains the best way to contain the spread of the virus.

All over the world, governments, as well as the government of Ghana have implemented lots of measures including lockdown on the basis of the severity of the pandemic to curtail its spread and flatten the curve $[1,19]$. The President of the Republic of Ghana, acting in line with the Imposition of Restrictions Act 1012, on the 30th of March, imposed restrictions on the movement of people in the Greater Accra Metropolitan Area including Awutu Senya East and the Greater Kumasi Metropolitan Area and its contiguous districts, for a period of two weeks, subject to review. The intention was to halt the spread of the virus and to effectively scale-up contact tracing of persons who are suspected to have come in contact with an infected case, to test them for the virus and if proven that they have the virus, to quarantine and isolate them for treatment. Indeed, the country's two leading commercial centers, thus Accra and Kumasi have been the most hit by the pandemic, with Accra notably recording the highest tally of positive confirmed cases. Fowler, Hill, Levin, and Obradovich report that lockdown is effective in curbing the spread of COVID-19, but it has huge impact on the economy [7]. To them, lockdown entails that businesses are closed and jobs are suspended (except those considered as essential services) and schools are also closed. However, Viner et al. stress that currently there is no available model or empirically-based report that shows positive correlation between closure of schools and curbing of the spread of COVID-19 [22].

On Sunday, $15^{\text {th }}$ March, 2020, the President of the Republic of Ghana in addressing the nation for the second time on the measures taken by his government to combat the spread of the Coronavirus pandemic announced that effective Monday, 16 ${ }^{\text {th }}$ March, 2020 all Universities, Senior High Schools, and basic schools, that is public and private schools, will be closed till further notice, even though Ghana as at that time had recorded just six (6) confirmed cases. The question that arose was how learners were going to make up for the period of lockdown since educational systems in the country are planned with specific calendars $[1,19]$. Indeed, a handful of educational institutions in the country have started using online teaching platforms such as MOODLE, Zoom, Google classroom and Google meet as useful means to ensure that learners are not denied access to education during this period of schools shut down. Almost three months after schools shut down, Ghana's president on his $10^{\text {th }}$ nation address on COVID-19 announced the reopening of schools, effective Monday, $15^{\text {th }}$ June, 2020. This was to allow final year student to resume classes ahead of their respective exit examinations [19]. This decision, according to him, was arrived at after stakeholder engagement with teachers unions, though the number of confirmed cases at the time stood at eight thousand and seventy $(8,070)$. To this end, this paper critically analyses the government policy guidelines towards the reopening of schools and the implicit role of teachers as frontline workers.

\section{Teachers' Role in Instructional Delivery}

The teaching profession is one of the oldest professions that even predates the establishment of school as an institution [9]. A teacher is the individual in the classroom who has the proficiency, tools and information necessary to edify students. Indeed, many a time, persons who enjoy respect in the society are selected for this dignified profession [9]. The role of the teacher in instructional delivery has proved to be priceless for students. The teacher is always expected to be a role model for the students and the society as a whole with his/her conduct and work [14]. Apart from the development of the pedagogical thought, teachers' works have always been in the focus of interest of renowned scholars who emphasize various aspects related to the role and the position of teachers. These related aspects require a teacher to possess knowledge, to be an educator, advisor, friend, organiser, coordinator, associate, assessor, in short, to be a versatile person [14]. More specifically, a teacher has a wider and more versatile role in the teaching and learning process. He/she should be active in school, outside school, during and after school activities. A good teacher does not impose his/her attitudes, however, his/her role also imposes on him/her to cooperate with students [5]. In fact, a good and democratic classroom environment implies that the teacher accepts the influence by the students.

In this era of technological explosion, there are abundant changes in teaching approaches along with the learning strategies. A teacher plays a very crucial role in developing a student's interest towards a subject. A teacher should thus become a learner by thinking about the situation, by understanding it through different point of views, before teaching students and by making them relevant in everyday circumstances. According to Xhemajli, a teacher does not only have educational and vocational roles but also has to be a designer, programmer, diagnostician, researcher, organiser, manager, innovator, educator and advisor [25]. More specifically, the teacher is the organiser of teaching and partner during the learning process. The teacher's job is to convince the student that education fulfills their needs [11, 
25]. He/she has to think from the learners' perspective before he/she plans to interact with the students [11]. When a teacher plans from the learners' perspective and starts teaching, students receive the information without any hesitation in grasping the concepts. Also, it is very significant that students begin to sense that their teacher is concerned about them and thus he/she becomes the best facilitator to the students in all aspects. As a facilitator, he/she has to direct and support students in learning as self-explorers. A teacher should develop best learning environment which reflects the students' life in societal, intellectual and linguistic occurrences [2]. Indeed, as a facilitator, a teacher should lay a strong foundation for students' personal growth.

Assessment is one of the important tools for extracting students' knowledge by giving continuous feedback. In fact, assessment is the only effective and potent tool for making students learning perfect. A teacher's role definitely will not complete just by teaching a lesson. He/she before assessing students has to first assess his/her own conclusions, as to what extent a student will benefit from his/her correct assessment $[1,2,19]$. These assessments can be carried out through verbal feedback, quizzes, tasks, or by observation. An assessment makes a teacher to plan for his/her future teaching techniques and in guiding him/her to master his/her area of specialization. A teacher's role as a manager is also a very significant and imperative in managing a class. A teacher has to plan well in advance regarding handling the classes within the stipulated time, covering academics as well as interpersonal skills with various teaching techniques which is obviously a path to practical approach [11]. An experienced teacher can manage the timings according to his/her own experience. Perfect classroom management by a teacher using the major mechanisms will lead to success of teaching and learning process. Lastly, it is an undeniable fact that evaluation plays a prominent role to a teacher's success. Evaluation is a subjective process, which is related to academics. A teacher has to be an effective evaluator while evaluating the student. Indeed, true and fair evaluation should be done by a teacher in order to do justice to a student's career [2]. As an evaluator, a student should also be focused on the areas of competence rather than on the weaknesses and every student should be viewed in the light of positive expectations. Undoubtedly, teachers play diverse roles in the teaching and learning enterprise and by performing these various roles, they becomes ideal guides in shaping students future even in this period of the outbreak of COVID-19.

\section{Teachers' Preparation Towards Reopening of Schools}

Since schools were first shut down in mid-March, educators have struggled to offer distance learning and adapt to the unique challenges COVID-19 poses. Schools, especially tertiary institutions in Ghana, resorted to distance learning programmes to facilitate dissemination of knowledge to their students [1]. However, this novel way of learning appeared to be froth with a myriad of challenges. Consequently, many students, educators and families have called for the reopening of schools. Reopening schools in a manner that is safe and responsive to the needs of families and communities will involve novel challenges. The President of Ghana on May 312020 announced that effective June 15, 2020 schools and universities will be reopened to allow final year junior high, senior high and university students to resume classes ahead of the conduct of their respective exit examinations [1]. This decision, according to him, was arrived at after engagement with the Teacher Unions. Amid the rush of urgent needs to partially open schools for final year students to prepare for their respective exit exams will require determined, creative, problem-solving by educators, Ghana Education Service (GES) and Ministry of Education to sketch a blueprint for reopening of schools. Unquestionably, educational workers, especially teachers must be fully prepared and psyched to be combat ready to act as first aiders in situations of suspected COVID-19 cases [19].

Prior to the opening of schools and universities, the President of Ghana directed the Ministry of Education to ensure that all public and private educational institutions are fumigated and disinfected. The President further directed that each student, teacher, and non-teaching staff should be provided with re-usable face masks. Immediately after this announcement, GES through its Director General came out with a comprehensive guidelines towards the reopening of schools. These guidelines had three fundamental principles (sick stay home; enhanced hygiene protocols, and face masking) to help keep students, teaching and non-teaching staff safe at school and help to stop the spread of COVID-19. Besides these guidelines, GES also highlighted ten general conditions, which included disinfection, provision of WASH facilities, provision of mask, mapping schools to health facilities, splitting of classes, ban on mass gatherings, sports and sporting events, schools not open to outsiders, no visitors and monitor school attendance, for the purpose of effective response to COVID-19.

Meanwhile, Teachers Unions in the country on May 26, 2020 tabled a proposal to GES on measures to curb the spread of the novel COVID-19. Even though, the four Teachers Unions, thus Ghana National Association of Teachers (GNAT), National Association of Graduate Teachers (NAGRAT), Teachers and Educational Workers Union (TEWU) and Coalition of Concern Teachers (CCT) indicated emphatically that they were not in favour of the reopening of schools due to current data on COVID-19 available to them, they wish to submit the proposal to government and GES should the GES decide to reopen schools regardless of the prevailing evidence of horizontal spread of the disease. The Teachers Unions' proposal contained nineteen (19) suggestions categorized under three thematic areas, thus short to intermediate and medium to long terms measures. Among the short to intermediate measures are: the testing of all staff and learners before schools reopen and those found to positive should not be allowed entry into 
the schools; provision of appropriate PPEs for teachers and learners; ensuring that all schools have good water and sanitation facilities, provision of free transport and most importantly, the provision of special incentives for teachers and by extension GES staff. However, the striking spectacle is that no adequate steps and measures have been taken on the part of government and GES to address the 19 suggestions, especially the crucial ones for teachers who risk their lives and act as frontline workers in instructional delivery in this unusual times. Indeed, the Teacher Unions request to the government to incentivize them emanates from a similar gesture that has been extended to health workers and other professionals (the security services) for their role as frontline workers.

Countries such as South Korea, Israel, Sweden, Denmark, etc. that reopened schools without comprehensive safety protocols experienced a quick school closure because many teachers and learners became exposed to COVID-19 [13]. In fact, Ghanaian educators' vulnerability to COVID-19 pandemic cannot in any way be overemphasized, raising questions about how to protect them and respond to any anticipated upsurge and to guarantee that teachers can work safely and productively [19]. Strategies to prevent COVID19 among educators in Ghana start with the training and education of teaching and non-teaching staff safety measures according to the updated protocols as issued by the WHO and Ghana Health Service. The education should include, information on the type of virus, its transmission, disease signs and symptoms, vulnerable groups and prevention and management protocols. Training workshop for teachers should include the proper use, cleaning, re-use of face masks and shields and personal hygiene. In addition, guidelines must be issued to protect individuals and prevent transmission of COVID 19 infection to teachers, nonteaching staff and learners. Moreover, standard cleaning and disinfection measures for classrooms, dormitories and staff bungalows should be performed religiously to further prevent the spread of the virus and minimize the risk of cross infection.

A critical aspect is the protection are teachers who may be at risk, including individuals more than 50 years old those with the presence of a systemic disease, smokers and those with disabilities [18]. Such teachers should be identified and given limited contact hours to prevent any eventualities. To protect such teachers and their families, they should undergo routine medical checks, including temperature checks and RT-PCR test. Also, they should advised to isolate themselves and maintain social distancing from family members, other staff and students on the slightest symptom of COVID-19 [13]. Undeniably, a key preventive measure for COVID-19 infections require specialized personal protective equipment (PPE). However, due to the large scale of infections globally, the supply of these PPEs has been irregular to say the least. Indeed, inadequate availability and improper use of PPEs is a critical contributory factor in the high COVID-19 infection rates among health workers in Ghana and globally. The concern therefore is that is the government and for that matter the president ready to go the extra mile to make these protective equipment available to teachers as a way of the president commitment to the wellbeing of teachers and for him to give full meaning to his famous quote “... we know how to bring the economy back to life but what we do not know is to bring human back to life".

\section{Infection Among Education Workers}

Statistics show that teachers come in contact with dozens of students each day and are recorded as having a significantly higher number of social interactions than those in other professions, putting them at greater risk of contracting the virus to begin with [3]. Indeed, reports of education workers infected with COVID-19 are emerging globally. Previous studies find that one in four teachers $(24 \%$ or about 1.47 million teachers) have a higher risk of infection from COVID-19 [13]. This percentage seems to be the same for all frontline workers. The challenge for school systems and for teachers in particular is the sheer volume of traffic and tight quarters in many school environments, which may make social and physical distancing a significant challenge in many setting. For higher risk teachers, failure to achieve safe working conditions could have very serious results. Given the difficulty of maintaining social and physical distancing in a crowded school environment, these at-risk teachers may be reluctant to their schools until infection rates fall to much lower levels. It is therefore imperative to prevent COVID-19 infections among teachers by taking appropriate measures as higher infection rates for teachers from different countries are showing increased risk.

From the above reports, it is clear that teachers are being increasingly infected with COVID-19. Teachers are at the forefront of the delivery of quality education amid the COVID-19 pandemic, working in close proximity with lots of students who may be potential carriers of the infectious virus [23]. Besides, the unpreparedness of the healthcare system and the novelty of this disease has made all frontline workers including teachers a common and easy target for these infections. One of the most important routes of secondary transmission of COVID-19 is the spread through a high traffic environment. A primary reason for teachers to get infected is the insufficient accurate scientific data on SARSCOV 2 including, its virulence factors, survival outside a host, resistant strains, incubation period and infection pathophysiology [10]. Reports from the early viral spread in the Chinese city of Wuhan have suggested that a high number of workers, who were unaware of the transmissibility and severity of COVID 19 got infected [10]. This was primarily due to the lack of information of the disease and its viral spread. In addition, the preventive measure for COVID 19 infections require specialized personal protective equipment (PPE) for protection from infections. Likewise, stressful working environment, long working hours leading to fatigue and isolation related psychological issues also contribute to increased probability for teachers' infection of COVID-19 [23]. Some other factors which can predispose teachers to 
infection could possibly be inadequately cleaned and sanitized hospital surfaces, compromise in disinfection of teaching and learning materials and lack of training and education related to the viral pandemic. Decision makers in the Ministry of Education and GES, and other stakeholders responsible for reopening of schools should weigh not only the health of the students, but also that of the teachers who are at elevated risk. In fact, assuring the safety of teachers and other education workers at higher risk of infection from COVID-19 is a crucial part of the calculation around school reopening.

\section{Impact on Education}

Education has been the bedrock of development of every nation; hence its sustainability is paramount to growth and development of all nations [16]. Education over centuries have been hit with several challenges ranging from changes in school curriculum to closing down of Educational Institutions due to either a demonstration by students or staff, outbreak of a disease and/or instability in governance of a nation of which the education system in Ghana is of no exception. Going to school is the best public policy tool available to raise skills [16]. While school time can be fun and can raise social skills and social awareness, from an economic point of view the primary point of being in school is that it increases a child's ability. Even a relatively short time in school does this; and even a relatively short period of missed school will have consequences for skill growth.

COVID-19 has become a health crisis and this crisis crystallizes the dilemma policymakers are facing between closing schools and keeping them open [22]. The impact of the Corona virus disease is now beginning to spread to the world of education. In fact, Coronavirus pandemic has affected educational systems worldwide, leading to the widespread closure of schools in the affected countries. As of May 30, 2020, over 1.8 billion learners were out of school due to closure of schools as a way to curb the spread of the pandemic. According to UNESCO (2020), over 100 countries have implemented nationwide closure of schools, impacting nearly $90 \%$ of the world's student population. School closure does not only affect students, teachers, and families, but have far-reaching economic and societal consequences [15, 20]. On March 3 2020, UNESCO released the first global numbers on school closure and affected students and it reported that 13 countries had sanctioned precautionary measures including the temporary closure of schools and universities. In view of this, UNESCO called on countries to support affected students and families and facilitate largescale inclusive distance learning programs. By March 10, one in five students worldwide was "staying away from school due to the COVID-19 crisis while another one in four was barred from higher education institutions" [20]. On March 13,2020 , governments in 61 countries announced the closure of schools. This included 39 countries which closed schools nationwide and 22 countries with localised closure of schools [20]. These countries increased from 61 to 73 a week later, according to UNESCO, of which Ghana was part of the countries that closed down schools on the said date [20]. UNESCO estimates 473,933,356 learners are potentially at risk (pre-primary to upper-secondary education) and $77,938,904$ learners are potentially at risk in tertiary education [20].

School closures in response to the COVID-19 pandemic have shed light on numerous issues affecting access to education [20]. According to Owusu-Fordjour, Koomson and Hanson, more than 370 million children and youth are not attending school because of temporary or indefinite country wide school closure mandated by governments in an attempt to slow the spread of COVID-19. School closures carry high social and economic costs as well as disrupt learning among students [19]. These disruptions affect people across communities, however their impact is more severe for disadvantaged children and their families including interrupted learning, compromised nutrition, childcare problems and consequent economic cost to families who cannot work [20]. Working parents are more likely to miss work when schools close in order to take care of their children, incurring wage loss in many instances and negatively impacting productivity [20].

\section{Citizens' Indifference to COVID-19 Safety Protocols}

Governments across the world in their frantic efforts to contain the further spread and the diffusion of the COVID-19 disease have taken measures that are unprecedented [26]. Strangely, entire cities, regions and countries are sealed off, travel is banned, schools and universities are closed, shops are running out of stocks, and all economic, cultural and social activities have come to a stop. In fact, never before in modern history of the world has a health problem had had such an overwhelming impact on society. At first sight, this pandemic and the world's response to it seems far remote from all health promotion protocols. Many of the measures that have been taken to prevent citizens and health workers from getting infected imply a change of behaviour [4]. That is, regular hand washing, wearing face masks/shields and protective gloves and social/physical distancing. Indeed, the fast and incessant progression of the COVID-19 disease and the scale of the measures that are put in place may, rightly or wrongly, create the impression that the existing health system is failing to protect citizens against the spread of the virus.

Empowering the citizens to increase control over their health and its determinants is at the core of health promotion [21]. Undoubtedly in times like this, such health promotions assume more important role than ever before. To contain the spread of the COVID-19 virus, the Ghana government through the health authorities have tried to enhance protective behaviours amongst citizens [1, 19]. First by issuing warnings and recommendations about the new virus, and at a later stage by imposing legal restrictions, in some areas experiencing a complete 'lock-down'. These measures 
have been met with varying degrees of success. At the inception of this pandemic, the citizens' responses to warnings was often weak and ineffective, thus wasting opportunities to effectively contain the spread of the disease. And even when the scale of the problem became pandemic, a significant number of people still failed to adhere strictly to the safety protocols. In Ghana, the blatant of these safety protocols among the youth is often condemned and seen as irresponsible and childish, but that needs not necessarily be the case. Changing people's behaviour is simply not as easy as just informing them of the risks but would also require constant reminders and monitoring.

Years of research in protective health behaviours show that people act on health warnings if they believe that they are personally susceptible to develop the condition against which protection is required; perceive the condition as severe; perceive the preventive action as effective to reduce the threat; and believe they are capable to perform the preventive action. It is clear that in the case of COVID-19 these conditions are not always fulfilled and many Ghanaian youth do not consider themselves at risk $[1,19]$. Indeed, a chunk of the youth have not been in contact with others who have contracted this deadly disease and therefore may underestimate the seriousness of this pandemic. This is couple with the fact that the government COVID-19 response team many a times make the citizenry believe that most fatalities are older people or people with pre-existing morbidity. Contrary, the wide coverage of the pandemic by the Ghanaian media and the scope of the preventive measures that are taken also create anxiety. While a certain level of concern is an important driver for protective behaviour, too much anxiety can elicit cognitive avoidance strategies which minimize the perceived threat [6]. In addition, an individual's social identity needs in interaction with contextual factors can increase and mitigate the actual rejection of evidence, a phenomenon that is known as knowledge resistance [12].

\section{Conclusion}

In the wake of the COVID-19 pandemic, most of the worldwide institutions have been affected ranging from economy, industries, religion and education, to mention few. Teachers are at the frontline in educational delivery amid the rising cases COVID-19 in the country. However, educational workers and for that matter teachers were ill-prepared before the reopening of schools. Earlier evidence suggests that teachers are being increasingly infected with COVID-19. Major factors accounting for COVID-19 infection among teachers include inadequate preparation before school reopening of schools, lack of understanding of the epidemiology of the disease, unavailability of PPEs, and psychological stress. We, therefore recommend that protection of students, teachers and nonteaching staff should be a topmost priority of the government through the education and training, provision of appropriate incentives, availability of PPEs and the provision of psychological support.

\section{Conflict of Interest Statement}

The authors declare that they have no competing interests.

\section{References}

[1] Addadzi-Koom, M. E. (2020). Quasi-state of emergency: assessing the constitutionality of Ghana's legislative response to Covid-19. The Theory and Practice of Legislation, 1-17.

[2] Archana, S., \& Rani, K. U. (2017). Role of a teacher in English language teaching (ELT). International Journal of Educational Science and Research (IJESR), 7 (1), 1-4.

[3] Barrero, J. M., Bloom, N., \& Davis, S. J. (2020). Covid-19 is also a reallocation shock (No. w27137). National Bureau of Economic Research.

[4] Bauchner, H., \& Sharfstein, J. (2020). A bold response to the Covid-19 pandemic: medical students, national service, and public health. Jama, 323 (18), 1790-1791.

[5] Craig, C. J. (2017). Sustaining teachers: Attending to the bestloved self in teacher education and beyond. In Quality of teacher education and learning (pp. 193-205). Springer, Singapore.

[6] Croyle, M. (2013). Back Injury Prevention among High School Cheerleaders at a Rural High School: Submitted to the Department of Occupational Therapy in Partial Fulfillment of the Requirements for the Degree of Master of Occupational Therapy (Doctoral dissertation, Saint Francis University).

[7] Fowler, J. H., Hill, S. J., Levin, R., \& Obradovich, N. (2020). The effect of stay-at-home orders on COVID-19 infections in the United States. arXiv preprint arXiv: 2004.06098.

[8] Freedman, L. (2020). Strategy for a Pandemic: The UK and COVID-19. Survival, 62 (3), pp. 25-76.

[9] Fafunwa, A. B. (2018). History of education in Nigeria. Routledge.

[10] Huang, B., Wu, A., Peng, Y., Ding, X., Wang, X., Niu, P., \& Sheng, J. (2020). Genome composition and divergence of the novel coronavirus $(2019-\mathrm{nCoV})$ originating in China. Cell host \& microbe.

[11] Keiler, L. S. (2018). Teachers' roles and identities in studentcentered classrooms. International Journal of STEM education, 5 (1), 34.

[12] Klintman, M. (2019). Knowledge resistance: How we avoid insight from others. Manchester University Press.

[13] Kuguyo, O., Kengne, A. P., \& Dandara, C. (2020). Singapore COVID-19 Pandemic Response as a Successful Model Framework for Low-Resource Health Care Settings in Africa? OMICS: A Journal of Integrative Biology.

[14] Lancaster, R. W. (2017). A comparison of student-centered and teacher-centered learning approaches in one alternative learning classroom environment. Arkansas State University.

[15] Lindzon, J. (2020). School closures are starting, and they'll have far-reaching economic impacts. Fast Company, 11-13.

[16] Malik, R. S. (2018). Educational challenges in 21st century and sustainable development. Journal of Sustainable Development Education and Research, 2 (1), 9-20. 
[17] Ochara, N. M. (2020). Contextualizing the Outcomes of COVID-19 Global Response. Available at SSRN 3607899.

[18] Owusu-Fordjour, C., Koomson, C. K. and Hanson, D. (2020). The impact of Covid-19 on learning-the perspective of the Ghanaian student. European Journal of Education Studies, 7 (3), 88-101.

[19] Salama, A. M. (2020). Coronavirus questions that will not go away: interrogating urban and socio-spatial implications of COVID-19 measures. Emerald Open Research, 2.

[20] United Nations Education Scientific and Cultural Organization (2020). COVID-19 Educational Disruption and Response. Retrieved from: https://en.unesco.org/covid19/educationresponse

[21] Van den Broucke, S. (2020). Why health promotion matters to the COVID-19 pandemic, and vice versa.

[22] Viner, R. M., Russell, S. J., Croker, H., Packer, J., Ward, J., Stansfield, C. \& Booy, R. (2020). School closure and management practices during coronavirus outbreaks including COVID-19: a rapid systematic review. The Lancet Child \& Adolescent Health.

[23] Willis, J., Krausen, K., \& Outlaw, L. (2020). Managing Public Education Resources during the Coronavirus Crisis: Practical Tips and Considerations for School District Leaders. Crisis Response Resource. WestEd. 19: a rapid systematic review. The Lancet Child \& Adolescent Health.

[24] World Health Organization, (2020). WHO consolidated guidelines on tuberculosis: tuberculosis preventive treatment: annex 3: grade evidence-to-decision tables (No. WHO/UCN/TB/2020.3). World Health Organization.

[25] Xhemajli, A. (2016). The role of the teacher in interactive teaching. International Journal of Cognitive Research in Science, Engineering and Education, 4 (1), 31.

[26] Zizek, S. (2020). PANDEMIC! Covid-19 Shakes the World. John Wiley \& Sons. 